\title{
Pressure-Induced Disorders in Neurotransmission and Spontaneous Behavior in Rats: An Animal Model of Psychosis
}

\author{
Jacques H. Abraini, Marc Ansseau, and Taoufiq Fechtali
}

\begin{abstract}
Disorders in neurotransmission and spontaneous behavior in rats exposed to a high pressure helium-oxygen mixture that shows interesting parallels with the dopaminergic hypothesis of schizophrenia at both the biochemical and the therapeutic responding levels are reviewed. Furthermore, as human subjects exposed to a very high pressure have shown psychotic episodes, we conclude that the pressure-induced disorders in neurotransmission and spontaneous behavior in rats could constitute a valid animal model of schizophreniform psychosis and a useful tool for both the investigation of the biological mechanisms underlying schizophrenia and the development of new antipsychotic drugs.
\end{abstract}

Key Words: Schizophrenia, animal model, high pressure, dopamine, amino acids

\section{Introduction}

One of the major handicaps in schizophrenia research today is the lack of valid and potent animal models (Ellenbroek 1991). In the present article, we review disorders in neurotransmission and spontaneous behavior in rats exposed to the high pressure of a helium-oxygen mixture that shows interesting parallels with the dopaminergic hypothesis of schizophrenia at both the biochemical and the therapeutic responding levels. A brief overview of highpressure biological research and of the dopaminergic hypothesis of schizophrenia will precede the description of the suggested animal model of schizophreniform psychosis.

From the Unité de Neuropsychiatrie, C.H.U. Sart Tilman, Liège, Belgium and CNRS URA 1630, Faculté de Médecine Nord, Marseille, France.

Address reprint requests to J.H. Abraini, Ph.D.; Laboratoire de Physiopathologie Intégrée et Cellulaire, CNRS URA 1630, Faculté de Médecine Nord, 13916 Marseille cédex 20, France.

Received December 7, 1992; revised June 15, 1993.

\section{High Pressure Biology}

The high ambient pressure of helium-oxygen is known as a basic etiological factor underlying central nervous system changes referred to as the high-pressure neurological syndrome. This syndrome is observed when human divers or experimental animals are exposed to pressure of more than 20 bars. The principal symptoms consist in biobehavioral disorders and electroencephalographic changes (Lemaire and Rostain 1988). Biobehavioral disorders consist in tremor; muscular jerks; disorientation; and sensorimotor, attention, and habituation deficits. Electroencephalographic symptoms mainly include an increase in slow-frequency activities and a decrease in the amplitude of the eventrelated potential P300 (Rallo et al 1989), which are electroencephalographic disorders classically described in schizophrenic patients (Itil 1977; Faux et al 1990). Moreover, recent data on divers exposed to very high pressure have also reported psychotic episodes defined as organic affective disorder (Stoudemire et al 1984) or hallucinatory psychosis (Raoul et al 1988; Douchet et al 1990). Although the nosology of these cases is still discussed, all of the 
subjects initially presented delusions, hallucinations, paranoid thoughts, and agitation. Interestingly, this clinical picture, which is suggestive of schizophreniform psychosis, responded to neuroleptics but not to benzodiazepines, in doses up to $120 \mathrm{mg}$ /day, or lithium (Stoudemire et al 1984).

In free-moving rats, biobehavioral disturbances mainly include locomotor and motor activity, which consist of ambulatory activity and hoarding behavior, tremor, and myoclonia (Tomei et al 1991). Elsewhere, rats also present coprophagous behavior (Abraini and Rostain 1991a). Furthermore, when compression is carried out, unrestrained or restrained animals also develop convulsions (for review see Halsey 1982).

The high-pressure neurological syndrome is considered to be a function of raised hydrostatic pressure and is exacerbated by the rate at which compression is applied. Many of its manifestations can be modulated pharmacologically. Neuronal hyperexcitability can be reduced by hypnotics, narcotic analgesics, anesthetic agents, and some inert gases at raised pressure (for review Halsey 1982), and can be exaggerated by analeptic drugs and lithium " (Bennett et al 1980). Conversely, high pressure reverses the narcotic effects of anesthetics and hypnotics (Halsey and Wardley-Smith 1975).

\section{Dopaminergic Hypothesis of Schizophrenia: Biological Data}

One of the predominant biological hypotheses of schizophrenia posits that the schizophrenic illness would be a manifestation of a hyperdopaminergic state (Matthysse 1973; Davis et al 1991). Recently, new evidence for this hypothesis has emerged from in vivo positron emission tomography studies (Wong et al 1986), and postmortem analysis of schizophrenic brains (Reynolds 1983). Moreover, several studies have also shown that nonmedicated schizophrenics do show an increase in dopaminergic (DA) levels or turnover, as experienced by increased concentrations in cerebrospinal fluid homovanilic acid (HVA) (Delisi et al 1987; Goldin et al 1987; Meltzer 1987). Furthermore, in drug-free schizophrenic patients, plasma HVA levels have been found to be correlated with the severity of psychotic symptoms (Davis et al 1985; Davidson and Davis 1988; Maas et al 1988).

In this field, it is particularly suggested today that the DA mesolimbic system would play a preponderant role in schizophrenia, and would be a target for the antipsychotic action of neuroleptics, whereas the nigrostriatal pathway would be the anatomical substratum of extrapyramidal side effects (Muller and Seeman 1978). This hyperdopaminergic state is partially supposed to be the consequence of an excessive burst firing of dopaminergic neurons (Grace
1991). Elsewhere, human postmortem studies supported that the D1-D2 link would be altered in schizophrenic patients. The influence of a D1 receptor would be reduced, because of an abnormal function and structure, and would allow an excessive number of D2 receptors to remain in a high-affinity state. As the high-affinity state constitutes the functional state of D2 receptors, it is suggested that high-affinity D2 states may be associated with the clinical condition of schizophrenia (Seeman et al 1989; Seeman and Niznik 1990). However, other works further suggested that such high-affinity D2 states would be effective only at the postsynaptic level, as D2 presynaptic receptors would present a reduced activity (Grace 1991).

At the therapeutic level, inhibition of dopamine synthesis fails to block schizophrenia; and presently, neuroleptic compounds, such as potent DA receptor antagonists, constitute the most effective treatment of the schizophrenic illness (Creese et al 1976). However, classical neuroleptics induce extrapyramidal side-effects, that is, involuntary and abnormal movements, in contrast to more recent compounds classified as atypical.

Nevertheless, contrary to the suggestion that there is an "absolute" overactivity of DA systems, other studies suggested that this would be only "relative" to a primarily reduced excitatory glutamatergic striatal and/or limbic input from the frontal cortex. Thus, in this field of hypothesis, low cerebral spinal fluid glutamate (Kim et al 1980), and glutamatergic deficiency in the frontal and temporal cortex of schizophrenic patients (Sherman et al 1991) have been demonstrated. Furthermore, increased N-methyl-Daspartate (NMDA) receptor density, that is, an activation of NMDA receptors, has been measured in the temporal and parietal cortex (Suga et al 1990), and the putamen (Komhuber et al 1989).

\section{Pressure-Induced Disorders in Rats: Parallels with Schizophrenia Data and Hypothesis}

We have recently demonstrated in vivo, in agreement with previous in vitro studies (MacLeod et al 1988; Paul and Philip 1989), that high pressure increased extracellular DA concentrations in the caudate-putamen (Abraini and Rostain 1991a) and the nucleus accumbens of rats exposed to high pressure (Abraini and Rostain 1991b) (Figure 1). Simultaneously, the animals developed behavioral motor disturbances such as locomotor and motor activity (LMA), which was correlated to the pressure-induced DA increase in both the nucleus accumbens $(r=0.982, p<0.001)$ and the caudate-putamen $(r=0.775, p<0.05)$, and myoclonia. This result favors a preponderant role of the nucleus accumbens, as compared to the caudate-putamen, in the occurrence and the development of LMA (Abraini 


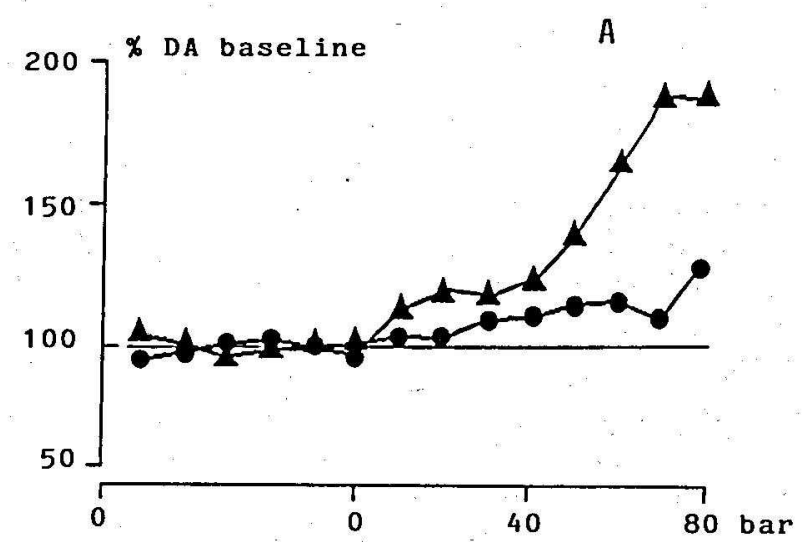

B

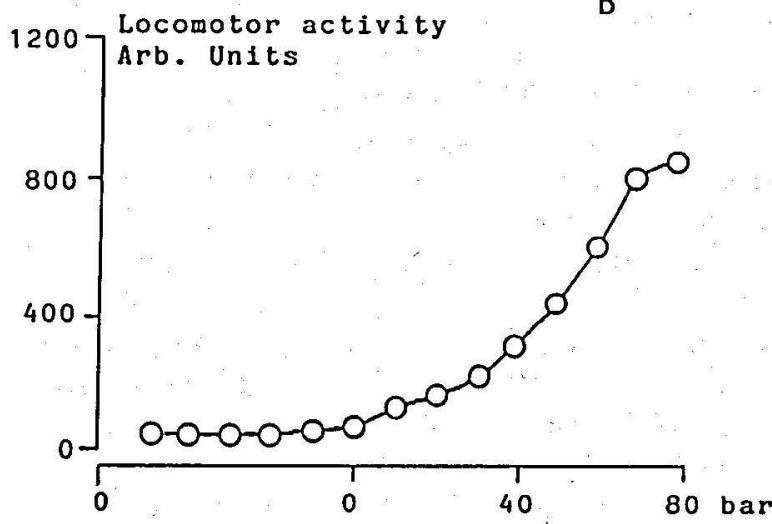

Figure 1. (A) Pressure-induced increase in DA release recorded from the nucleus accumbens $(A)(n=4 ; p<0.01)$ and the caudate-putamen $(O)(n=6 ; p<0.05)$ of free-moving rats exposed to 80 bars: (B) Development of the locomotor and motor activity (LMA) in free-moving rats exposed to high pressure (O). The development of LMA is correlated to the increase of DA in both the nucleus accumbens $(r=0.982, p<0.001)$ and the caudate-putamen $(r=0.775, p<0.05)$.

Rats were compressed to 80 bars at a rate of $1 \mathrm{bar} / \mathrm{min}$ in plexiglass individual cylinder in a $50-\mathrm{L}$ pressure chamber, according to a conventional technique: oxygen was maintained at a constant partial pressure of 0.4 bar; temperature was increased throughout the experiment from 25 to $34^{\circ} \mathrm{C}$ and humidity controlled between $50 \%-70 \%$ to maintain the comfort of the animals. Decompression was at a rate of $0.06 \mathrm{bar} / \mathrm{min}$ from 80 bars to 12 bars and $0.04 \mathrm{bar} / \mathrm{min}$ from 12 bars to normal pressure. During decompression, partial pressure of oxygen was 0.5 bar. In all cases, the animals survived to the pressure experiments. DA release was monitored using differential pulse voltammetry and a classical three-electrode potentiostatic system with electrochemically pretreated DA-selective carbon electrodes (El Ganouni et al 1987) implanted under general anesthesia (pentobarbital $30 \mathrm{mg} / \mathrm{Kg}$ ). DA voltammograms were recorded every $3 \mathrm{~min}$, and DA release was expressed as a percentage of the mean of a 2 hr period of control before pressure exposure, taken as the $100 \%$ value. LMA was deduced from piezo-electrical sensors fixed under the floor of each individual cylinder analyzed using a computerized device, and expressed in arbitrary units (Tomei et al 1991). and Rostain 1991b). Because it has been clearly demonstrated that the pressure-induced increase in DA release was the consequence of an increase DA synthesis (Paul and Philp 1989), one can postulate that the hyperdopaminergic states in both the caudate putamen and the nucleus accumbens could be the consequence of an increased firing of dopaminergic neuronal cells.

Pressure investigations performed with DA receptor agonists have shown that pressure exposure reversed the decrease in striatal DA release induced by the specific D1 receptor agonist SKF 38393, and the specific D2 receptor agonist LY 171555 [which is expected to act selectively on D2 presynaptic receptors (Walters et al 1987)], although it failed to change the effect of the activation of both D1 and D2 receptors by apomorphine or mixed (SKF 38393 + LY 171555) (Abraini et al 1992) (Figure 2). This suggested pressure-induced "blockade-like" abnormal functions of D1 and D2 presynaptic receptors. As SKF 38393 did not prevent the pressure-induced increase in DA release, whereas apomorphine or mixed (SKF 38393 + LY 171555) did, this further suggested that the D1-D2 postsynaptic link would be reduced under high pressure. If so, a reduced influence of D1 receptors could allow an excessive number of D2 postsynaptic receptors to remain in the high-affinity state for DA. Finally, in agreement with previous pharmacobehavioral observations which reported that D2 postsynaptic, but not presynaptic, receptors would be highly activated under high pressure (Abraini et al 1991d), it is suggested that such a preponderance of high-affinity D2 states would be associated with LMA in rats exposed to high pressure, as this behavioral disturbance has been demonstrated to be correlated to the pressure-induced DA increase.

At the "therapeutic" level, inhibition of DA synthesis by administration of a-methyl-p-tyrosine delayed the occurrence of LMA, but failed to counteract its final development in spite of decreased levels of DA (Figure 3) (Abraini and Rostain 1991c). Alternatively, neuroleptic compounds dramatically blocked LMA (Figure 4); however, typical neuroleptics such as haloperidol significantly enhanced myoclonia (which consist as indicated above in involuntary muscular jerks), whereas atypical neuroleptics such as SCH 23390 or sulpiride decreased it (Figure 5) (Abraini et al 1991d).

Beyond these dopaminergic disturbances in rats, pressure exposure has been shown to decrease glucose metabolism in the frontal cortex, although it enhanced glucose metabolism in the striatum (Brauer et al 1981). Elsewhere, other authors have clearly demonstrated that high pressure significantly decreased glutamate release in hippocampal brain slices (Zinebi et al 1988), and furthermore that NMDA receptor activity was highly potentiated under high pressure (Meldrum et al 1983; Fagni et al 1987; Millan et al 

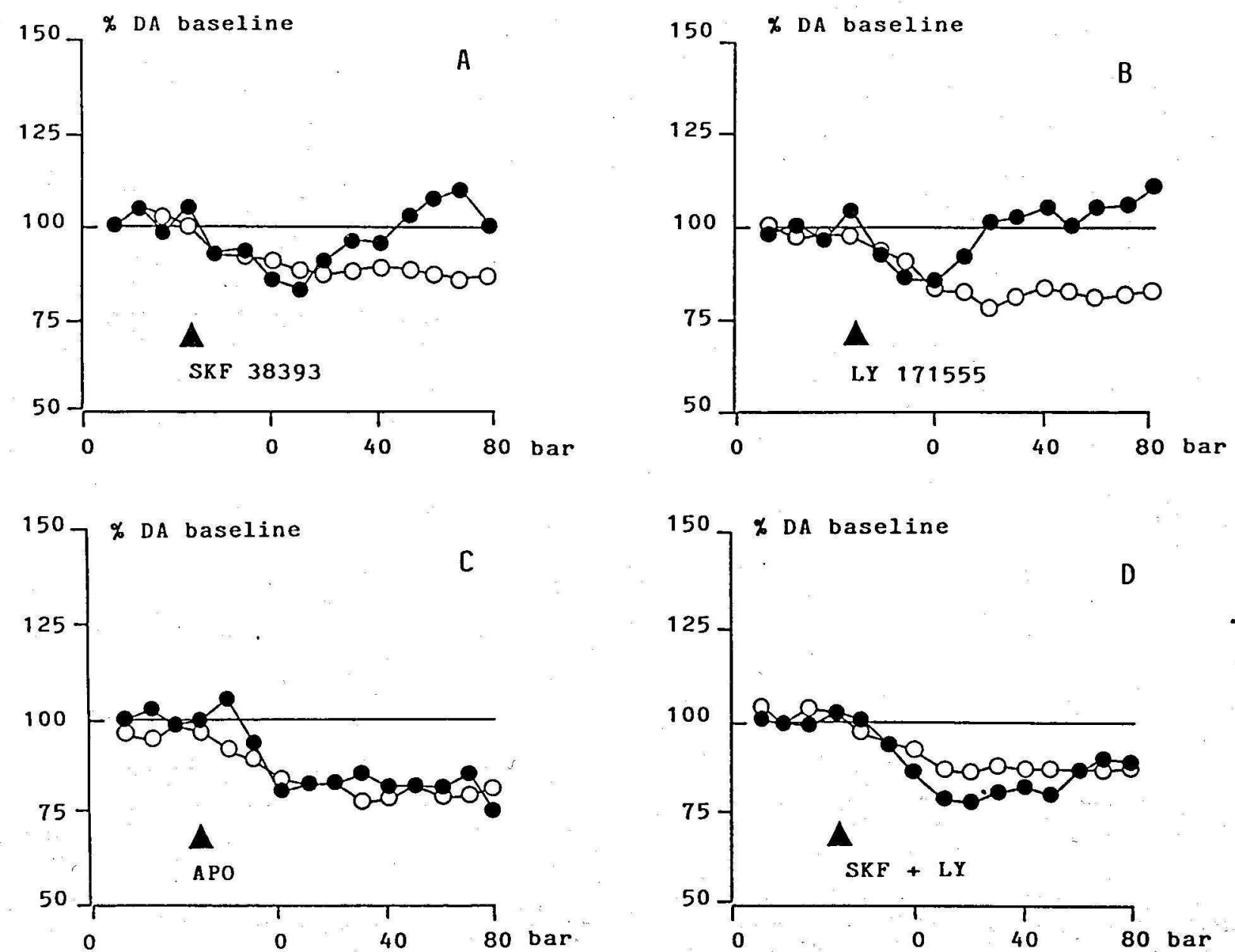

Figure 2. Effects of pressure on DA release recorded from the caudate-putamen of free-moving rats injected with DA receptor agonists at $10^{-8} \mathrm{~mol}$, such as SKF 38393, a D1 receptor agonist; LY 171555, a D2 receptor agonist; apomorphine, a D1/D2 receptor agonist; or mixed (SKF 38393 + LY 171555). In each case, (O) represents control experiments at normal pressure $(n=6)$; and $(O)$ represents pressure experiments $(n=4)$. (A) shows the reversal effect of pressure on the SKF 38393induced DA decrease as compared to normal pressure control experiments: (B) represents the reversal effect of pressure on the LY 171555-induced DA decrease as compared to normal pressure control experiments: (C) and (D) respectively, show the persistent effect of apomorphine and mixed (SKF $38393+$ LY 171555) under high pressure $(p<0.01)$. DA voltammograms were recorded every $3 \mathrm{~min}$, and DA release was expressed as a percentage of the mean of a 2 -hr period of control before drug administration, taken as the $100 \%$ value.

$1989,1990)$. In these conditions, as suggested for schizophrenia, the pressure-induced dopaminergic disorders recorded in the nucleus accumbens and the caudate-putamen could be related to a reduced excitatory glutamatergic function, possibly from the frontal cortex (Abraini and Fechtali 1992).

\section{Discussion}

The present animal model of schizophreniform psychosis is based on parallels between the dopaminergic hypothesis of schizophrenia in humans and pressure-induced neuro- biological symptoms in animals. However, although several of the features reported above are shared with schizophrenia, there are also marked differences. Indeed, the general central nervous system impairment induced by pressure exposure appears to be more characteristic of toxic psychosis than of schizophreniform psychosis. For instance, a symptom such as depression of P300 is common with other nonrelated attentional disorders; furthermore, other symptoms have much in common with a toxictype psychosis, as exemplified by the characteristic of disorientation or myoclonia, which are not consistent with a true schizophrenia-like psychosis. Also, animals exposed 
\% DA baseline
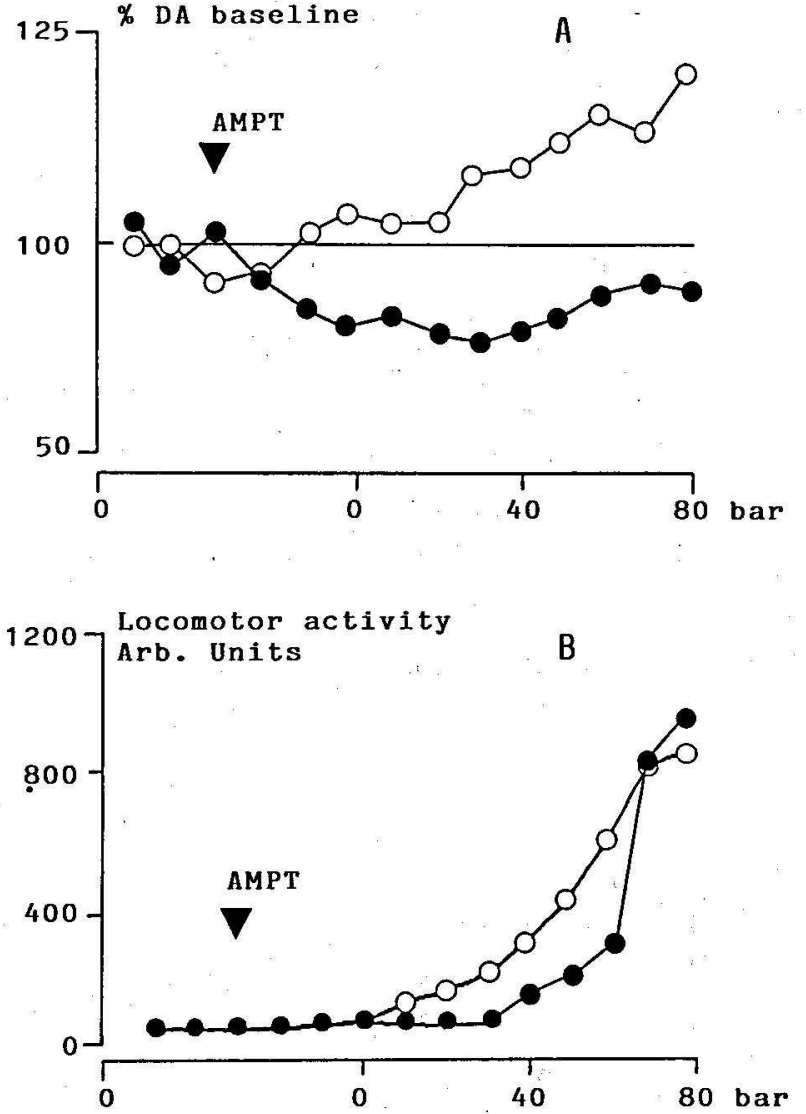

Figure 3. Neurochemical and behavioral effects of the administration of a-methyl-p-tyrosine (AMPT) at $10^{-7} \mathrm{~mol}$ in rats exposed to 80 bars. Pressure control experiments are represented by (O); (O) represents AMPT experiments. (A) AMPT administration significantly decreased striatal DA release $(n=4 ; p<$ $0.05)$ as compared to control rats $(n=6)$ : (B) AMPT administration significantly delayed the occurrence of LMA $(n=4$; $p<0.05$ ), but failed to block its final development as compared to control rats $(n=6)$.
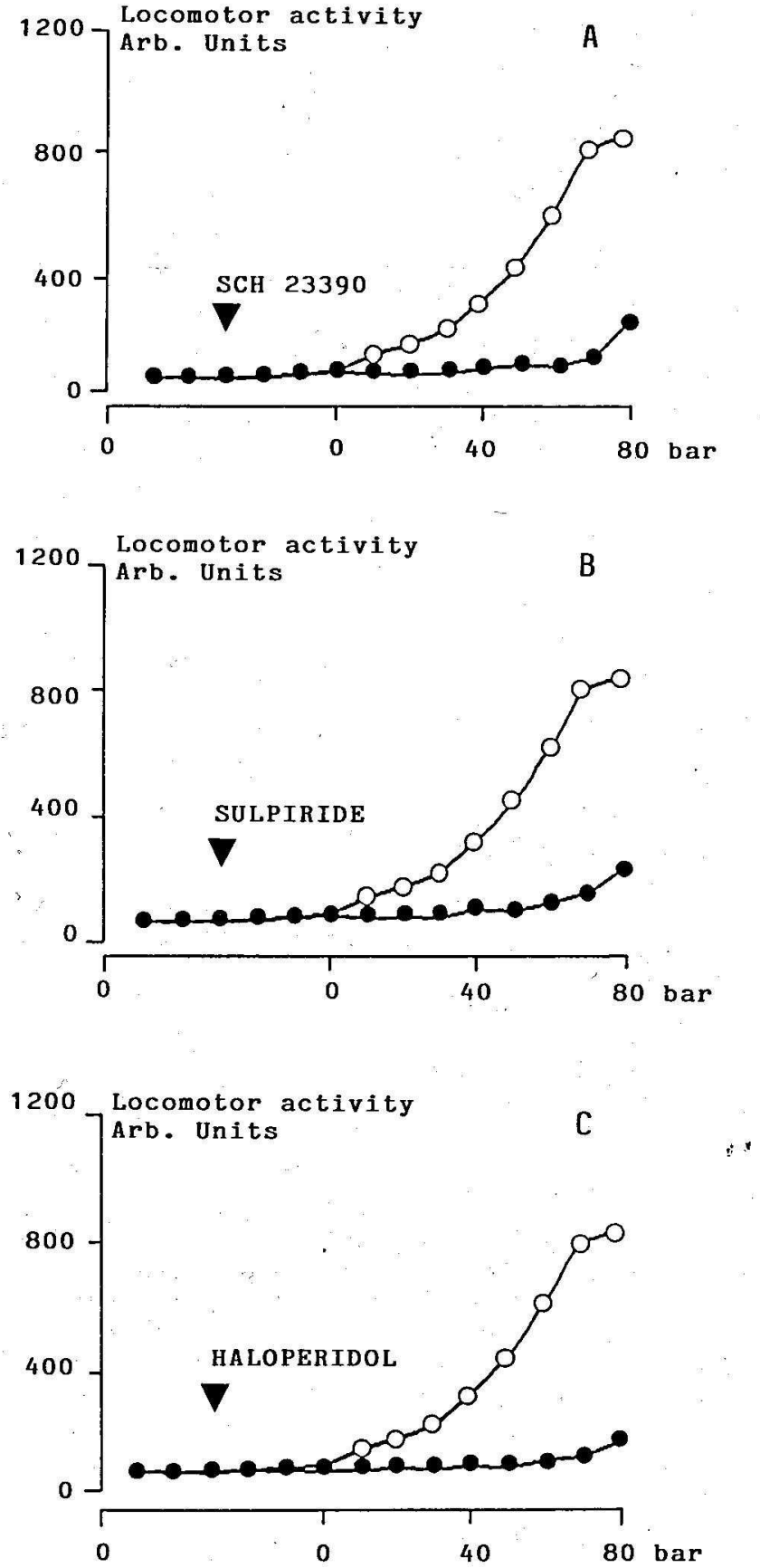

Figure 4. Effect of the administration of DA receptor antagonists at $10^{-8} \mathrm{~mol}$ on the pressure-induced locomotor and motor activity (LMA) in rats exposed to 80 bars. Neuroleptic compounds such as SCH $23390(n=4)(\mathrm{A})$, sulpiride $(n=4)(\mathrm{B})$, or haloperidol $(n=4)(C)$ dramatically decreased the development of LMA $(p<0.01)$ as compared to control $(n=6)$. Pressure control experiments are represented by $(\mathrm{O}) ;(\mathrm{O})$ represents neuroleptic experiments. 


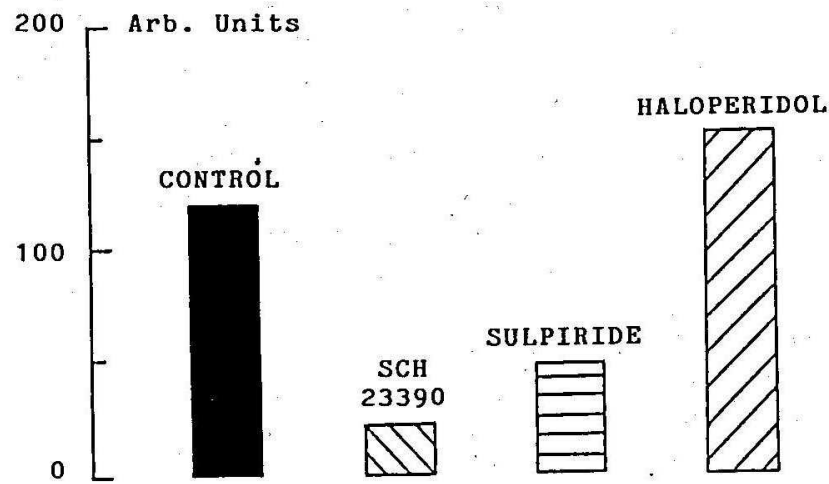

Figure 5. Effects of the administration of DA receptor antagonists on the pressure-induced myoclonia in free-moving rats exposed to 80 bars: atypical compounds such as SCH 23390 ( $n=$ 4 ) and sulpiride $(n=4)$ decreased myoclonia as compared to control $(n=6)$ (respectively, $p<0.01$, and $p<0.05$ ), whereas a classical one such as haloperidol $(n=4)$ enhanced it $(p<$ $0.05)$ as compared to control data $(n=6)$. Myoclonia were deduced from piezo-electrical sensors fixed under the floor of each individual cylinder, analyzed using a computerized trigger, and expressed in arbitrary units (Tomei et al 1991).

$\times 3$

to high pressure have been clearly demonstrated to be less sensitive to narcotics and anesthetics, whereas schizophrenics are normoresponsive to these agents.

Moreover, although new evidence for the dopaminergic hypothesis of schizophrenia has emerged from in vivo positron emission tomography studies (Wong et al 1986), postmortem analysis of schizophrenic brains (Reynolds 1983), and analysis of cerebrospinal fluid HVA concentrations in nonmedicated schizophrenics (Delisi et al 1987; Goldin et al 1987; Meltzer 1987), there are several studies that have failed to demonstrate an increase in DA levels or turnover in schizophrenic patients by measuring cerebrospinal fluid HVA concentrations (Bowers 1974; Post et al 1975), whereas a pressure environment induced such an increase in turnover. In these conditions, the specificity of pressure-induced in vivo phenomena for DA must be therefore examined. In this regard, stressful environmental situations are well known to lead to activation of the DA systems. This seems presently not to be the case as similar increases in DA release have been also demonstrated in vitro in striatal brain slices exposed to high pressure (MacLeod et al 1988; Paul and Philp 1989). Furthermore, in rats exposed to high pressure inhibition of DA synthesis significantly delays the occurrence of LMA (Abraini and Rostain 1991c), which is correlated to the pressure-induced DA increase in both the nucleus accumbens and the caudate-putamen.

Alternatively, the fact that the administration of DA receptor antagonists (i.e. neuroleptics) dramatically blocked pressure-induced LMA is not specific for a dopaminergic action, since these drugs also act at other neurotransmitters, such as serotonin, and will inhibit locomotion irrespective of its origin.

However, in conclusion, although it is impossible to speak about schizophrenia in rats, and despite the present animal model of schizophreniform psychosis shows several limiting factors, the animal data exposed above presents unique parallels to the dopaminergic hypothesis of the schizophrenic illness at both the biochemical and therapeutic responding levels. Thus, the pressure-induced disorders in neurotransmission and spontaneous behavior could therefore constitute a useful tool for the investigation of the physiopathology of schizophreniform psychosis and the development of new antipsychotic drugs.

Abraini JH, Fechtali T, Rostain J-C (1992): Pressure reverses extracellular striatal dopamine decrease produced by $\mathrm{D} 1$ receptor agonist SKF 38393, and D2 receptor agonist LY 171555 , but failed to change the effect of the activation of both DI and D2 receptors. Neuroscience 50:395-402.

Bennett PB, Leventhal GL, Goggin R (1980): Lithium effects: protection against nitrogen narcosis, potentiation of HPNS. Undersea Biomed Res 7:11-16.

Bowers M (1974): Central dopamine in schizophrenic syndromes. Arch Gen Psychiatry 31:50-54.

Brauer RW, Mansfield WM Jr, Beaver RW, Gillen HW (1981): The HPNS as composite entity-consequences of an analysis of the convulsion stage. In Bachrach AJ, Matzen MM (eds). Underwater Physiology VII. Bethesda, MD: Undersea Medical Society, pp 391-399.

Creese EI, Burt DR, Snyder SH (1976): Dopamine receptor binding predicts clinical and pharmacological potences of antischizophrenic drugs. Science 192:481-483. 
Davidson M, Davis KL (1988): A comparison of plasma homovanilic acid concentrations in schizophrenic patients and normal controls. Arch Gen Psychiatry 45:561-563.

Davis KL, Davidson M, Mohs RC (1985): Plasma homovanilic acid concentration and the severity of schizophrenic illness. Science 227:1601-1602.

Davis KL, Kahn RS, Ko G, Davidson M (1991): Dopamine in schizophrenia: a review and reconceptualization. Am J Psychiatry 148:1474-1486.

Delisi LE, Goldin LR, Gershon ES (1987): Studies of biological factors associated with the inheritance of schizophrenia: a selective review. J Psychiatry Res 21:507-513.

Douchet J-C, Raoul Y, Trividic A, et al (1990): Psycho-activité de l'hydrogène en pression. In Plongée Humaine en Mélange Hydrogène-Oxygène dite Hydra IX (DRET report no89-1305). Toulon-naval: C.E.R.B.

El Ganouni S, Forni C, Nieoullon A (1987): In vitro and in vivo characterization of the properties of a multifiber carbon electrode allowing long-term electrochemical detection of dopamine in freely-moving animals. Brain Res 404:239-256.

Ellenbroek BA, Cools AR (1991): Animal models for schizophrenia. In Racagni G, Brunello N, Fukuda T (eds), Biological Psychiatry, vol. 2. Amsterdam: Excerta Medica, pp 605607.

Fagni L, Zinebi F, Hugon M (1987): Helium pressure potentiates the N-methyl-D-aspartate and D,L-homocysteate-induced decreases of field potentials in the rat hippocampal slices preparation. Neurosci Lett 81:285-290.

Faux SF, Shenton ME, MacCarley RW, et al (1990): Preservation of $\mathrm{P} 300$ event-related potential topographic asymmetries in schizophrenia with use of either linked-ear or nose reference sites. Electroenceph Clin Neurophysiol 75:378-391.

Goldin LR, Delisi LE, Gershon ES (1987): Unravelling the relation between genetic and environmental risk factors in psychiatric disorders. Br J Psychiatry 151:302-305.

Grace AA (1991): Phasic versus tonic dopamine release and the modulation of dopamine system responsivity: A hypothesis for the etiology of schizophrenia. Neuroscience 41:1-24.

Halsey MJ (1982): Effects of high pressure on the central nervous system. Physiol Rev 62:1341-1377.

Halsey MJ, Wardley-Smith B (1975): Pressure reversal of narcosis produced by anaesthetics, narcotics and tranquilizers. Nature 257:811.

Itil T (1977): Qualitative and quantitative EEG findings in schizophrenics. Schizophr Bull 3:61-79.

Kim JS, Kornhuber HH, Schmid-Burgk W, Holzmuller B (1980): Low cerebral spinal fluid glutamate in schizophrenic patients and a new hypothesis on schizophrenia. Neurosci Lett 20:379382.

Kornhuber J, Mack-Burkhardt F, Riederer P, et al (1989): 3HMK801 binding sites in post-mortem brain regions of schizophrenic patients. J Neural Transm 77:3231-236.

Lemaire C, Rostain J-C (1988): The High Pressure Nervous Syndrome. Marseilles: Octares Publications.

Maas JW, Contreras SA, Seleshi E (1988): Dopamine metabolism and disposition in schizophrenic patients. Arch Gen Psychiatry 45:553-559.
MacLeod M, Bennett PB, Cooper RL (1988): Rat brain catecholamine release at $1,10,20$, and 100 ATA heliox, nitrox, and trimix. Undersea Biomed Res 15:211-221.

Matthysse S (1973): Antipsychotic drug actions: a clue to the neuropathology of schizophrenia? Fed Proceed 32:200.

Meldrum BS, Wardley-Smith B, Halsey M, Rostain J-C (1983): 2-amino-7-phosphonoheptanoic acid protects against the high pressure neurological syndrome. Eur J Pharmacol 87:501502.

Meltzer HH (1987): Biological studies in schizophrenia. Schizophr Bull 13:77-97.

Millan MH, Wardley-Smith B, Halsey MJ, Meldrum BS (1989): Studies on the role of NMDA receptor in the substancia nigra pars retuculata and entopenduncular nucleus in the development of the high pressure neurological syndrome in rats. Exp Brain Res 78:174-178.

Millan MH, Wardley-Smith B, Halsey MJ, Meldrum BS (1990): Effect of NMDA and 2-amino-7-phosphonoheptanoate focal injection into the ventrolateral thalamic nucleus on the high pressure neurological syndrome in the rat. Brain Res 507:354 356.

Muller P, Seeman P (1978): Dopaminergic supersensitivity after neuroleptics: time-course and specificity. Psychopharmacology $60: 1-11$.

Paul ML, Philp RB (1989): Hyperbaric He but not N2 augments $\mathrm{Ca} 2+$-dependent dopamine release from rat striatum. Undersea Biomed Res 16:293-304.

Post R, Fink E, Carpenter W, Goodwin F (1975): Cerebrospinal fluid amines metabolites in acute schizophrenia. Arch Gen Psychiatry 32:1063-1069.

Rallo JL, Perlin M, Rostain J-C, Lemaire C (1989): Changes in ERPs components recorded under $\mathrm{He}-\mathrm{O} 2$ and $\mathrm{He}-\mathrm{N} 2-\mathrm{O} 2$ during a dive at $450 \mathrm{msw}$. In Rostain J-C, Martinez E, Lemaire C (eds), High Pressure Nervous Syndrome, 20 Years Later. Marseilles: ARAS-SNHP Publications, pp 51-57.

Raoul Y, Meliet JL, Broussolle B (1988): Troubles psychiatriques et plongee profonde. Med Armees 16:269-270.

Reynolds GP (1983): Increased concentrations and lateral asymmetry of amygdala dopamine in schizophrenia. Nature 305:527.

Seeman P, Niznik HB (1990): Dopamine receptors and transporters in Parkinson's disease and schizophrenia. FASEB $J$ 4:2737-2744.

Seeman P, Niznik HB, Guan HC, Booth G, Ulpian C (1989): Link between $\mathrm{D} 1$ and $\mathrm{D} 2$ receptors is reduced in schizophrenia and Huntington diseased brain. Proc Natl Acad Sci USA 86:10156-10160.

Sherman AD, Davidson AT, Baruah S, Hegwood TS, Warizi R (1991): Evidence of glutamatergic deficiency in schizophrenia. Neurosci Lett 121:77-80.

Stoudemire A, Miller J; Schmitt F, et al (1984): Development of an organic affective syndrome during a hyperbaric diving experiment. Am J Psychiatry 141:1251-1254.

Suga I, Kobayashi T, Ogata H, Toru M (1990): Increased 3HMK801 binding sites in post-mortem brains of chronic schizophrenic patients. New Trends in Schizophrenia and Mood Disorders Research. Kyoto: p 28.

Tomei C, Abraini JH, Rostain J-C (1991): A new device for 
behavioral analysis on rats exposed to high pressure. Physiol Behav 49:393-396.

Walters JR, Bergstrom DA, Carlson JH, Chase TN, Braun AR (1987): D1 dopamine receptor activation required for postsynaptic expression of D2 agonist effects. Science 236:719722.

Wong DF, Wagner HN, Tune LE, et al (1986): Positron emission tomography reveals D2 elevated dopamine receptors in drugnaive schizophrenics. Science 234:1558.

Zinebi F, Fagni L, Hugon M (1988): The influence of helium pressure on the reduction induced in the field potentials by various amino acids on the GABA-mediated inhibition on the CA 1 region of the hippocampal slices. Neuropharmacology 27:57-65. 